\title{
VIVENDO O SOFRIMENTO E OS DESAFIOS NO TRABALHO: EXPRESSÕES AUTOCRÍTICAS DE UM GRUPO DE ENFERMEIROS-EDUCADORES
}

\author{
LIVING THE SUFFERING AND CHALLENGES IN THE WORK: SELF-CRITICAL OPINIONS \\ OF A NURSE-EDUCATORS GROUP
}
VIVENDO EL PADECIMIENTO Y LOS DESAFÍOS EN EL TRABAJO: EXPRESIONES AUTOCRIITICAS DE UN GRUPO DE ENFERMEROS-EDUCADORES.

\section{Claudiniete Maria da Conceição Bezerra Vasconcelos ${ }^{1}$ \\ Marta Lenise do Prado ${ }^{2}$}

\begin{abstract}
RESUMO: Este é um recorte da minha dissertação de mestrado, que teve como objetivo conhecer as expressões autocríticas de enfermeiros-educadores sobre seu processo de trabalho, na formação de técnicos de Enfermagem. A metodologia utilizada como referencial foi a concepção construtivista, sócio-interacionista de Vygotsky e reuniu expressões de um grupo docente profissional de Enfermagem atuante em um Estado da Região Sul do Brasil. Foram realizadas sessões temáticas e sistemáticas com os sujeitos deste estudo e exploradas as narrações feitas a respeito de suas respectivas vivências pedagógicas. Como procedimento de análise foi adotado o método proposto por Trentini, Paim. Os resultados apontam que esses enfermeiros-educadores expressam o prazer de lidar com a educação profissional voltado a formação de técnicos de Enfermagem e o sofrimento de um processo de trabalho implicado em desvalorização de múltiplas ordens. Além disso, revelam os indicativos de organização interna de uma rede social, interacionista entre os sujeitos desse nível de educação com tendência a contínua construção de mudanças dirigidas à competência pedagógica desse grupo.
\end{abstract}

PALAVRAS-CHAVE: Enfermagem; Expressões autocríticas; Processo de trabalho.

ABSTRACT: This is a cutting of my máster, thisl had as objective to know the nurses-educators self-critical expressions concerning the working process on professional teaching for technical nursing. was based on the constructive, social-interactive conception by Vygotsky, which assembled expressions from a nursing teaching group who works in a Brazilian South region state. There were carried out thematic and systematic meetings with the subjects of this study where their reports about their respective pedagogical experiences were explored. It was used the method proposed by Trentini and Paim as an analysis procedure. The results point out that these nurseseducators express their pleasure of working with technical nursing teaching. They also show that the different kind of problems they face during the working process can lead them to all sort of devaluation. Apart from this, the results point out some aspects that are indicatives of internal organization of a social institution as interactive among the subjects of this education level. It also shows that this kind of organization seems to keep changing the pedagogical competence of this group.

KEY WORDS: Nursing; Self-critical expressions; Working process.

RESUMEN: Esta es uma reseña de mi disertación de maestría que tuvo como objetivo conocer las expresiones autocríticas de enfermeros-educadores sobre sus proceso de trabbajo em la formación de técnicos Enfermería. La metodologia usada como referencial fue la concepción constructivista, sócio-interacionista de Vygotsky y reunió expresiones de um grupo de docente profesional de Enfermería que actua em um Estado de la región sul del Brasil. Fueron realizadas sesiones temáticas y sistemáticas com los sujetos de este estudío y exploradas las narraciones hechas al respecto de sus respectivas vivencias pedagógicas. Como procedimiento de análisis fue adoptado el método propuesto por Trentini, Paim. Los resultados apuntan que esos Enfermeros-educadores expresan el placer de lidar con la educación profesional volcado a la formación de técnicos de Enfermería y el sufrimiento de um proceso de trabajo implicado em la desvalorización de múltiples ordenes. Además de eso, revela los indicativos de organización interna de uma red social interaccionista entre los sujetos de esse nivel de

\footnotetext{
${ }^{1}$ Mestre em Enfermagem - Área de concentração Filosofia, Saúde e Sociedade/ UFSC. Professora da Universidade do Planalto Catarinense -UNIPLAC, Membro do Grupo de Pesquisa EDEN/UFSC, 2003. e-mail: claudiniete@superig.com.br

2 Dra. em Enfermagem. Professora Adjunta do Departamento de Enfermagem e do Programa de Pós-Graduação em Enfermagem da Universidade Federal de Santa Catarina - UFSC. Orientadora do trabalho. Pesquisadora do ÉDEN/UFSC. email: mpradop@nfr.ufsc.br
} 
educación com tendencia a la continua construcción de mudanzas dirigidas a la competencia pedagógica de esse grupo.

PALABRAS CLAVE: Enfermeria; Expresiones autocríticas; Proceso de trabajo.

\section{AO INICIAR A TRAJETÓRIA COMPARTILHO COM AS IDÉIAS DE ALVES...}

"É essa a imagem que se forma ao redor de minha paixão pela educação: estou semeando as sementes da minha mais alta esperança. Não busco discípulos para comunicar-Ihes saberes. Os saberes estão soltos por aí, para quem quiser. Busco discípulos para neles plantar minhas esperanças, e quando os sonhos assumem forma concreta, surge a beleza e minha paixão pela educação" (ALVES, 2001, p. 11).

\section{E, COM SEUS SONHOS}

Pois, toda estréia gera expectativas, inseguranças, medo e desejo de realizações. Mas, "para navegar não basta sonhar. Se os barcos se fazem com ciência, a navegação se faz com sonho" (ALVES, 2001, p. 74). Continuando a trajetória, senti que chegou o momento da grande decisão, para onde navegar? Naveguei no rumo certo? $\mathrm{Na}$ trajetória percebi, que não há certo ou errado - há rumos e decisões. De toda sorte o mais decisivo é continuar seguindo, ir navegando em barcos, ir sonhando com ciência...

\section{REFLETINDO PROBLEMÁTICA}

ACERCA

Nas últimas décadas, tem-se passado por metamorfoses significativas em todas as áreas do conhecimento humano. $\mathrm{Na}$ educação, o ensino de Enfermagem se vê hoje diante de múltiplas visões paradigmáticas, constituindo-se num espaço polêmico de transição, no qual se dão esforços e opções entre as diferentes Escolas pedagógicas e sua pertinência às práticas profissionais nesta área profissional. Estas práticas se caracterizam pela troca de um ensino verticalizado por uma escola interativa, onde a principal característica é a valorização do educando como cidadão e capital humano para o mundo do trabalho.

Ao pensar em educação e sua relação com o processo de trabalho, observo a importância a respeito da efervescência de novas práticas de saúde e de cuidar no mundo profissional de Enfermagem, que marcam os tempos atuais, permitindo visualizar o efeito de transição entre o ensino e a prática. De um lado, esses efeitos de transição, situados na saúde e na educação em Enfermagem impõem aos enfermeiroseducadores um rítimo desgastante de incertezas, de insegurança quanto ao seu destino nas instituições de saúde, de ensino e na sociedade, marcados pela dificuldade de inserção e pela exclusão no mercado de trabalho. Por outro lado, esses efeitos de transição, mostram as implicações ao reconhecimento dos próprios exercentes de Enfermagem, uma vez que eles são determinados e ratificados em lei pela estratificação dos diversos níveis da categoria.

Direcionando o meu olhar para a Enfermagem, objeto do meu interesse, deparei-me com algumas questões, tais como: Qual tem sido o processo de trabalho do enfermeiro educador frente a esta realidade? Estes enfermeiros que atuam na prática de ensino estão preparados para essa mudança, que é vista como algo necessário no dia-dia? O que fazer então para superar a contradição em nossa prática profissional? Estão orientados por uma ética das relações humanas no ensino e na práxis dos futuros profissionais de Enfermagem? Será que foram capacitados para enfrentarem os conflitos e as relações encontradas no processo de trabalho no contexto educacional e social? Quais têm sido as crenças e os valores que orientam a prática pedagógica 
dos enfermeiros-educadores de ensino Técnico em enfermagem?

Nesta perspectiva, penso que os limites de um artigo, no sentido de possibilitar a abordagem de todas as variantes do processo de trabalho do enfermeiroeducador, não se esgotam aqui. Contudo, espero que estas laudas possam expressar, ainda que não na sua integralidade, o que representou todo o processo de reflexão, criação, recriação e montagem deste ensaio, pois apesar das limitações buscou inserir o grupo de enfermeiros-educadores na construção desta proposta coletiva.

Diante o exposto, este estudo teve como objetivo conhecer as expressões autocríticas de um grupo de enfermeiros-educadores sobre seu processo de trabalho durante a prática de ensino, na formação de técnicos de Enfermagem.

\section{ALGUNS CONTORNOS DO CAMINHO...}

O caminho metodológico percorrido através da investigação, procurou sua completude num exercício de busca, de criação e recriação do processo do processo de trabalho, que objetivou a construção do saber, pressupondo-se que, o uso de uma metodologia que privilegia as ações críticas e reflexivas articuladas a realidade, contribuiu para transformá-la.

Foi estudo de natureza qualitativa, com abordagem descritiva e reflexiva, que teve que teve como teve como questão norteadora o seguinte problema de pesquisa: Como os enfermeiros refletem sua práxis ao exercerem o trabalho de educadores com práticas pedagógicas na formação profissional de enfermagem no nível médio? Como referencial foi utilizado a concepção construtivista, sócio-interacionista de VYGOTSKY (2000) e reuniu expressões de um grupo docente profissional de Enfermagem atuante em um Estado da Região Sul do Brasil, no período compreendido de março a julho de 2001.

Como procedimento de coleta e análise dos dados foi adotado o método
Convergente-Assistencial segundo TRENTINI \& PAIM (1999), aliado ao método construtivista proposto por SIQUEIRA et al (2000), é composto por três etapas: $1^{a}$ Etapa: Ponto de partida; $2^{\mathrm{a}}$ Etapa: Dialogicidade gerando conhecimento; $3^{\mathrm{a}}$ Etapa: Parar Retornar, sistematizando os passos utilizados nessa metodologia.

Estes passos foram significativos, pois a trajetória teórico-metodológica reuniu as estratégias e as técnicas destinadas a obter as informações, proposições críticas, quais sejam: encontro coletivo de vivências e registros através de Notas de Campo e Notas do Pesquisador, possibilitando o reconhecimento de nossa realidade educacional, a escolha do grupo de enfermeiros-educadores, as escolas participantes, a coleta e análise interpretativa dos dados.

Também sustentou, durante todo o processo, uma estreita relação com a situação social que foi pesquisada durante a disciplina Prática Assistencial em Enfermagem, me propiciando não somente a tarefa de facilitadora e organizadora do estudo, de me sentir parte dele, tendo plena interação com os participantes envolvidos no desenvolvimento dos diálogos, nas discussões, nas trocas de informações e nos relatos das experiências vivenciadas, vislumbrando a partir da reflexão, a construção coletiva e contínua, a elaboração inicial da primeira redação do relatório e a possibilidade de transformar a prática vigente, tendo em vista que a dinamicidade da prática assim 0 exige. Isto implicou construir conhecimentos numa ação partilhada, já que as relações entre sujeito e objeto do trabalho e as relações entre sujeitosujeito do conhecimento foram estabelecidas. Neste sentido, VYGOTSKY (2000) destaca a importância da experiência partilhada, da comunhão de situações, do diálogo, da colaboração, concebendo, o aprendizado como um processo de trocas e, portanto, verdadeiramente social.

As questões éticas foram precedidas da autorização formal dos participantes, que são 
identificados através de codinomes por eles escolhidos e, das escolas envolvidas através do Termo de Consentimento Livre e Esclarecido, de acordo com a Resolução 196/96.

Neste contexto, o desenvolvimento de uma atitude ética passou pela percepção dos inúmeros conflitos vividos pelo grupo, por um lado, pelo que "dizia o coração", e por outro, pelo que a "cabeça pensava". Em outros termos, ser ético é poder percorrer o caminho entre a emoção e a razão, posicionando-se de modo autônomo, na busca de uma posição integrada, compatível com a prática e as experiências vividas.

Os dados foram ordenados, categorizados, interpretados e analisados, obedecendo as etapas proposta por Trentini e Paim, quais sejam: Processo de Apreensão e Fase de Interpretação. Esta fase inclui três processos, discriminados como síntese, teorização e transferência.

Foi assim, na perspectiva do método proposto para leitura dos dados, que chegamos as Expressões Autocríticas do grupo, as quais foram analisadas gerando as categorias e as sub-categorias, nos remetendo às concepções do processo ensino-aprendizagem; o processo de trabalho e as relações de trabalho, bem como, o compromisso social é ético do grupo de enfermeiros-educadores das escolas estudadas.

Importante salientar que no âmbito deste estudo entendemos por "Expressões Autocríticas", a manifestação das crenças e valores, visão de mundo/filosofia de vida e o conhecimento tácito, técnico e científico do grupo de enfermeiros-educadores participantes, bem como, seu compromisso social, político, ético e estético, quando desenvolve sua prática pedagógica com os educandos do nível técnico de Enfermagem.

\section{EXPRESSÕES AUTOCRÍTICAS DO GRUPO DE ENFERMEIROS-EDUCADORES}

Da análise dos dados emergiram as seguintes categorias: 1) Educar: processo aprender/ensinar; 2) Vivendo o sofrimento e desafios no trabalho; 3) Construindo o comportamento moral e revelando o compromisso social, desvelando a partir destas, as diversas subcategorias. Para efeito deste ensaio, apresento as subcategorias que emergiram da categoria: Vivendo o sofrimento e desafios no trabalho, a saber: (Desmotivação e Não entusiasmo; Encanto e paixão; Manter-se preparado; Relações e condições de trabalho; Processo de viver saudável). Dentre estas, neste artigo, estão destacadas apenas três: Desmotivação e Não entusiasmo; Encanto e paixão; Relações e condições de trabalho.

\section{- Vivendo o sofrimento e desafios no trabalho...}

Observou-se que os enfermeiroseducadores convivem com vários fatores (necessidades sentidas) que geram angústia e sofrimento no trabalho, destacando-se: a má remuneração; inexistência do vínculo empregatício com as escolas; condições de trabalho deficientes; conflitos nas relações de trabalho; o preconceito dos profissionais de enfermagem nas instituições de saúde, principalmente, do enfermeiro com relação ao docente de nível técnico e superior; inconsistência entre a proposta políticopedagógica das escolas e sua implementação efetiva, gerando desorganização pedagógica-administrativa; déficit na formação didático-pedagógica dos enfermeiros-educadores e desvalorização social do trabalho, entre outros.

Para melhor compreendermos e analisarmos a questão é preciso que saibamos que estes profissionais encontram dificuldades ao atuarem na prática de ensino, no tocante a refletir, transmitir, compreender e ser compreendido pelo educando, no tocante ao tratamento e avaliação dos problemas pedagógicos que surgem no cotidiano, em aulas teórico-práticas nas instituições de ensino e na prática supervisionada nas instituições de saúde. 
Quando nestas circunstâncias, o educando é do nível técnico profissional, parece que a problemática torna-se mais crítica: $O$ que falar? Como falar? E como apoiá-lo sob a ótica pedagógica? Isto se torna visível na fala de conscientização.

"Sofro muito quando estou dando aula, passando os conteúdos ou fazendo trabalho em grupo ou prova e, parece que o aluno não está entendendo nada. Você explica diversas vezes, mas, parece que ele não compreende. Então, você precisa que a escola te auxilie, mas parece que ela não percebe esses fatos" (Conscientização).

Observa-se através desta expressão, que parece ser necessário que a escola favoreça o trabalho do enfermeiro-educador, proporcionando suporte adequado, tanto em termos financeiros e didáticos quanto pedagógicos, ou seja, disponibilize recursos financeiros dignos e condizentes com o ofício, material necessário que propicie condições de trabalho e capacitação técnicopedagógica, para que os educadores possam lidar com as dificuldades que surgem durante o processo de trabalho.

Pois, entre o homem e a organização prescrita para a realização do trabalho existe às vezes, um espaço de liberdade que autoriza uma negociação, invenções e ações sobre a organização do trabalho, para adaptá-la às suas necessidades, e mesmo para torná-la mais congruente com seus desejos. Logo esta negociação é conduzida a seu último limite e a relação homemorganização do trabalho fica bloqueada, começando o domínio do sofrimento e da luta contra o sofrimento (DEJOURS, 1994).

O sofrimento no trabalho afeta 0 comportamento dos profissionais na sua relação com os educandos, com as demais relações de trabalho das escolas e com seus próprios colegas de trabalho. Compromete também, a qualidade do ensino que é desenvolvido com os educandos e principalmente, causa desgaste ao profissional na sua atuação pedagógica. Em alguns casos, o educador não percebe que está sofrendo com esses conflitos que a organização do trabalho o submete, e isso gera expectativas de insatisfação pessoal e profissional em relação ao seu trabalho.

"A gente observa quando está com os alunos que o enfermeiro da prática esta desiludido, desestimulado por várias questões: é a sobrecarga de trabalho. É o salário miserável que recebemos. É o pessoal da equipe de Enfermagem, que estão oprimidos naquele local de trabalho e você não pode fazer nada, porque também, está na mesma situação. Mas com tudo isso, eu não largo a Enfermagem por nada" (Senso Comum).

Através desta expressão, percebemos que o reconhecimento dos outros pelo esforço do trabalho realizado, a valorização da entrega subjetiva do sujeito pode dar sentido ao sofrimento no trabalho, metamorfoseando esse sofrimento em prazer. Se isto não acontece, a procura de um prazer substituto ao desprazer experimentado no trabalho é de fato uma estratégia, e deve ter conseqüências sobre a atividade do trabalho do enfermeiroeducador. No entanto, ele poderia fazer uma outra opção para tentar mudar essa realidade do trabalho, ou seja, negando ou enfrentando o sofrimento no trabalho.

Todavia, os enfermeiros-educadores mesmo convivendo com tantos fatores que geram desmotivação e sofrimentos, apontam como um dos desafios deste processo os diferentes processos de trabalho que se complementam. Desta forma, o trabalho deve ser visto de forma coletiva ou cooperativa, o que nem sempre significa compreender ou dominar o processo de trabalho como um todo.

Embora tenhamos a compreensão que o processo de trabalho possa ser assim, coletivo ou cooperativo, é importante o estabelecimento de vínculo afetivo-emocional típico de situações sociais que dizem respeito à vida privada das pessoas e das boas relações de trabalho. Pois o que se exige dos sistemas educacionais modernos, 
atualizados, empreendedores é que possuam percepção, e sejam capazes de compreenderem e atuarem na dinamicidade do real como instituições políticas e produtivas. Que tenham conhecimento científico e consciência de seus direitos e deveres para dominar a natureza e transformar as relações sociais.

Torna-se perceptível em algumas expressões, que o enfermeiro-educador acomoda e encobre seu ser, ocultando-se em sua cotidianidade, no tocante ao trabalho educativo. Este, não constrói e não determina o seu fazer porque não é sujeito, mas objeto de seu próprio trabalho.

Isto também, se torna visível quando Dialética em sua fala diz:

"Inúmeras vezes em nossa prática, percebemos que o enfermeiro está receoso, com medo de assumir aquele estágio ou disciplinas teóricas por falta de experiência, pois, é recém-formado ou por não dominar o processo de trabalho com relação a prática de ensino, mas a escola insiste, tendo em vista que ela não tem ou não quer contratar outro professor, e ele acaba cedendo e os erros são muitos e compromete toda escola, os alunos e os docentes que nela estão atuando, gerando incertezas, falta de credibilidade dos profissionais que estão atuando naquela escola e que o mercado de trabalho exige competente" (Dialética).

Fica evidente, que mesmo se submetendo ao sistema imposto pela instituição de ensino e de saúde, uma vez que esta determina a sua atuação, o enfermeiro-educador percebe que seu processo de trabalho exige competência profissional e muito comprometimento e, qualquer que seja o ângulo abordado sobre esta realidade, há muito a ser repensado. A partir daí, a primeira questão a ser repensada é que o saber, o saber-fazer e o saber ser, estão na mão do enfermeiro-educador, condição principal de sua atividade de trabalho. Por isso, o planejamento de seu trabalho relacionado ao processo ensinoaprendizagem, deve ser decidido por ele.

Daí pressupor, que no momento da execução do processo de trabalho ao atuar na prática pedagógica, os enfermeiroseducadores estão obrigatoriamente interagindo com o seu objeto de trabalho (os educandos) e com o produto do trabalho que é a própria relação estabelecida no processo ensino-aprendizagem. A aprendizagem é a finalidade do trabalho que resulta desse processo de interação que transforma a ambos, educadores e educandos, e os meios de trabalho, que são os equipamentos, os materiais didático-pedagógicos, os conhecimentos disponíveis. Quando isso acontece, o processo de trabalho se inicia e se completa em uma relação direta, imediata e estritamente social.

Acredito também, que quanto maior a defasagem entre o trabalho como deve ser, e a realidade do trabalho nas escolas, maior será o investimento afetivo e cognitivo exigido ao educador, maior será o esforço realizado, e por isso, maior será seu sofrimento no cotidiano do trabalho. Esse sofrimento terá sentido para o enfermeiro-educador quando seu saber, saber-fazer e saber ser, que é constantemente interpelado durantes as atividades de trabalho, derem lugar a um reconhecimento e auto-reconhecimento da sua competência profissional. Inclusive, além dos resultados alcançados, quando seu esforço for reconhecido, significando que seu trabalho foi pleno de sentido.

\section{- Desmotivação e Não entusiasmo...}

Ao analisar esta subcategoria, observouse que alguns enfermeiros estão desmotivados para o trabalho, uma vez que não demonstram muito entusiasmo ao atuarem na prática pedagógica de formação profissional em Enfermagem. Poucos têm o privilégio de buscar a realização através do trabalho livre e sem explorações. Na verdade, a busca e aceitação de mais um emprego pela maioria dos enfermeiros-educadores deste grupo, são no sentido de ter condições e dar condições de subsistência a sua 
família. Estes fatos tornam-se visíveis quando Paradoxo diz:

"Observo quando estou com os alunos na prática que o enfermeiro e a equipe de Enfermagem do hospital, da prática estão desiludidos, desestimulados, desmotivados e insatisfeitos por várias questões: como a sobrecarga de trabalho, com o pessoal da equipe de enfermagem que está oprimido naquele local de trabalho e não estão nem aí para o cliente, com o salário miserável que recebem. Mas você tem que segurar a barra, pois sua situação também não é diferente". (Paradoxo)

O que se observa através destas expressões é que a grande desmotivação e o pouco entusiasmo que os profissionais demonstram, estão relacionados principalmente, a questão financeira, o gerenciar os conflitos que o novo traz, sendo que desta forma, o educador não se compromete com o trabalho, nem com os educandos, pois este se torna mais um meio de subsistência. Daí pressupor-se, que o sofrimento no trabalho afeta também, o comportamento dos enfermeiros educadores, desmotivando-os na sua relação com a organização do trabalho, uma vez que observamos através das expressões, e concluímos que é a organização que determina as relações entre desejo e motivação para o trabalho.

Sendo assim, qual é o lugar do docente no trabalho e de que liberdade ele dispõe para elaborar um compromisso nos conflitos que surgem no confronto de sua personalidade e de seu desejo com organização do trabalho? Será que ser educador/a é ainda uma opção de vida entusiasmante?

Cabe mencionar, que "o ambiente pedagógico tem de ser lugar de fascinação e inventividade. (...) Precisamos reintroduzir na escola o princípio de que toda morfogênese do conhecimento tem algo a ver com a experiência do prazer. Quando esta dimensão está ausente, a aprendizagem vira um processo meramente instrucional. (..)
Mas a experiência de aprendizagem implica, além da instrução informativa, a reinvenção e construção personalizada do conhecimento. E nisso o prazer representa uma dimensãochave" (ASSMANN, 2001; p. 29).

Por outro lado, o sofrimento no trabalho compromete a qualidade do ensino que é desenvolvido com os educandos, e principalmente, causa desgaste ao profissional na sua atuação pedagógica. Mas em alguns casos, o educador não percebe que está sofrendo com esses conflitos que a escola o submete, e isso gera insatisfação pessoal e profissional em relação ao seu trabalho, como observado na fala de Dialética.

"Penso que gerenciar os conflitos que o
novo traz é muito difícil às pessoas
aceitarem, mas não é impossível. As
pessoas estão acostumadas naquela
'mesmice' alienadas no tempo e espaço.
Então quando chegam idéias novas, as
pessoas ficam com dificuldade de
assimilarem. Isso gera muitos conflitos e
insatisfação" (Dialética).

Olhando sob esta ótica, percebemos que "o trabalhador não chega a seu local de trabalho como uma máquina nova. Ele possui uma história pessoal que se concretiza por uma certa qualidade de suas aspirações, de seus desejos, de suas motivações, de suas necessidades psicobiológicas, que integram sua história passada. Isso confere a cada indivíduo características únicas e pessoais" (DEJOURS, 1994; p. 24).

\section{- Encanto e Paixão...}

Ao analisar esta subcategoria, vislumbramos as dimensões de prazer, encanto, paixão e alegrias no ambiente pedagógico, divergindo em muitos aspectos da subcategoria anterior. Alves costuma dizer que educar tem a ver com sedução, e que o mestre nasce da exuberância da felicidade. Quando perguntam qual a sua profissão, responde: "Sou pastor da alegria" (ALVES, 2000). 
Ele pergunta ainda, o que é um professor, na ordem das coisas? (...) "Talvez que um professor seja um funcionário das instituições que gerenciam lagoas e charcos, especialista em reprodução, peça num aparelho ideológico de estado. Um educador, ao contrário, é fundador de mundos, mediador de esperanças, pastor de projetos" (ALVES, 2000; p 37).

É por essas ordens das coisas que o autor visualiza, que o grupo revela seu encanto e paixão em suas expressões:

"O que me apaixonou no ensino profissional de Enfermagem, foi o que vi na $62^{a}$ Semana Brasileira de Enfermagem, (...). Devia ter mais ou menos 30 enfermeiros, 20 alunos do nível superior, no entanto, do nível técnico tinha mais de 250 alunos. Acho que se alguém vai mudar alguma coisa na Enfermagem, esse alguém não é o enfermeiro, ou os alunos da graduação, e sim os alunos do ensino técnico. Fico encantada em participar do processo de formação de pessoas que já fazem a diferença na nossa profissão" (Utopia).

Percebe-se que os enfermeiroseducadores buscam através do sofrimento alguns mecanismos de defesa que funcionam como respiradouro, tais como: a valorização e o reconhecimento do educando (a) no processo ensino-aprendizagem. Estas expressões podem ser uma forma de mediação entre o prazer e o sofrimento no trabalho, contrapondo-se as necessidades sentidas que geram sofrimento no trabalho. No entendimento do grupo, são mecanismos de defesa que utilizamos no cotidiano, de forma a compensar as situações que geram sofrimento no trabalho.

Neste sentido, não é indispensável retomar aqui a análise da "psicodinâmica do reconhecimento. Basta conhecer-lhe a existência para discernir o papel fundamental que desempenha no destino do sofrimento no trabalho e na possibilidade de transformar o sofrimento em prazer". (...) "Do reconhecimento depende na verdade 0 sentido do sofrimento. Quando a qualidade de meu trabalho é reconhecida, também meus esforços, minhas angústias, minhas dúvidas, minhas decepções, meu desânimo adquire sentido. Todo esse sofrimento, portanto, não foi em vão; não somente prestou uma contribuição à organização do trabalho, mas também fez de mim, em compensação, um sujeito diferente daquilo que eu era antes do reconhecimento" (DEJOURS, 1994, p. 34).

Pois, "O sofrimento de ser um professor é semelhante as dores de parto: a mãe o aceita e logo dele se esquece pela alegria de dar à luz um filho".(...) "O educador, pelo menos 0 ideal que minha imaginação constrói, habita um mundo em que a interioridade faz uma diferença, em que as pessoas se definem por suas visões, paixões, esperanças e por seus horizontes utópicos" (ALVES, 2000, p. 20).

\section{- Relações e condições de trabalho...}

Ao analisar a subcategoria a partir das relações de trabalho dos enfermeiroseducadores, constatamos através de suas expressões, que no mundo contemporâneo, para se adequar ao ambiente de trabalho, é preciso maior entendimento entre os sujeitos do trabalho. Além disso, eles precisam ser valorizados, respeitados e considerados como dimensões essenciais na constituição, construção e desenvolvimento de todos os processos, dentre eles o processo de trabalho.

A organização do trabalho deve ser vista, antes de qualquer coisa, como uma relação socialmente construída e não somente em sua dimensão estritamente tecnológica, cognitiva ou física. Neste sentindo, a organização do trabalho aparece, antes de tudo, como uma relação intersubjetiva e uma relação social e isto, exige sempre, reajustes e reinterpretações pelos atores sociais. A intersubjetividade também aparece no próprio centro da organização do trabalho, e esta é, definitivamente determinada pelas relações sociais de trabalho. 
A intersubjetividade "é fundamentada em seu modelo de homem no trabalho. O homem é virtualmente um sujeito, e um sujeito pensante. Ele não é um joguete passivo as pressões das organizações, em virtude de um determinismo sociológico ou tecnológico vulgar. Fundamentalmente, o sujeito pensa sua relação no trabalho, produz interpretações de sua situação e de suas condições, socializa essas últimas em atos intersubjetivos, reage e organiza-se mentalmente, afetiva e fisicamente, em função de suas interpretações, age, enfim, sobre o próprio processo de trabalho e traz uma contribuição à construção e evolução das relações sociais de trabalho" (dejours, 2001, p. 40).

Sob esta ótica, as relações de trabalho do grupo de enfermeiros-educadores se dão justamente neste terreno de dupla troca entre a objetividade do mundo real, que concretiza o ato para o indivíduo, e a subjetividade do ser humano, que atribui um significado ao mundo real ao modificá-lo através de sua ação.

Estas relações englobam assim, esta tensão entre a objetividade do mundo real e a subjetividade do indivíduo que o realiza. $O$ que vai configurar esta tensão são as características específicas do próprio trabalho, uma vez que cada relação de trabalho, possui uma dinâmica própria, onde as possibilidades de expressão humana vão variar em maior ou menor grau.

Estas tensões ficaram explícitas através das expressões de Senso comum:

"A maior dificuldade nas relações de trabalho envolve a questão financeira, pois os donos de escolas pagam muito mal o professor e exigem qualidade. $A$ escola deveria ter era um quadro de professores permanentes, fazer as capacitações técnica e pedagógica dos docentes, bem como trabalhar as questões, interagindo professor, aluno, direção da escola e coordenação técnica e os campos de estágios" (Senso Comum).
Observa-se através das expressões, que parece necessário estabelecer melhor as relações de trabalho dos enfermeiroseducadores com a escola para favorecer o exercício da autonomia profissional, oportunizando ambientes mais adequados e organizados, com condições humanas (dignas e éticas) e materiais suficientes (instrumentos de trabalho), possibilitando alcançar maior qualidade e produtividade ao desenvolver o seu trabalho.

Neste sentido, LUNARDI FILHO (1997), reportando-se às idéias de Dejours, coloca que a organização do trabalho é de certa forma a expressão da vontade do outro. O trabalhador domesticado e forçado a agir conforme a vontade do outro, é desprovido de seu corpo físico e desprovido de sua competência, uma vez que ao ocupar um cargo na organização, já tem estabelecido uma série de tarefas a cumprir, bem como os objetivos e os meios. Assim, o trabalho está determinado, restando-Ihe apenas executá-lo.

Percebe-se que dentre os fatores que dificultam as relações de trabalho, encontrase 0 preconceito que alguns enfermeiros sofrem dentro das instituições de saúde onde estão atuando com os educandos.

"Percebo que o maior dificultador nas
relações de trabalho é o preconceito
que as pessoas tem quanto ao
professor do nível técnico,
principalmente os próprios colegas
enfermeiros, do hospital. Quando a
gente chega com os alunos, dizem, ela
é professora do técnico e isso atrapalha
e muito. Ainda bem que isso ocorre
somente em algumas instituições de
saúde" (Utopia).

$E$ que, entre o homem e a organização prescrita para a realização do trabalho, existe, às vezes, um espaço de liberdade que autoriza uma negociação, invenções e ações de modificação do trabalho, para adaptá-la às suas necessidades, e mesmo para torná-la mais congruente com seu desejo. Logo que a negociação é conduzida a seu último limite, e que a relação homem-organização do trabalho fica bloqueada, começa o domínio 
do sofrimento e luta contra o sofrimento (DEJOURS, 2002).

No processo de trabalho do enfermeiroeducador a autonomia no e para o trabalho, também precisa ser vista como um espaço de liberdade, de criatividade, para discutir, analisar, articular e definir áreas prioritárias de atuação, bem como, um espaço para a produção de conhecimentos a partir da realidade. Esta atuação é teorizada, pensada e planejada no que diz respeito aos procedimentos didáticos, os métodos e a utilização dos recursos de ensino. Neste sentido, 0 processo de trabalho do enfermeiro-educador, passa a ser caracterizado como uma prática social e política.

A questão da autonomia ficou explicitado na expressão de Diferença:

"Vejo a questão da autonomia como crucial no processo de trabalho do professor, obviamente, este fundamentado em algum referencial/teoria. A utilização de recursos didático-pedagógicos para sua atuação, permite a possibilidade de idéias inovadoras e criativas, fazendo com que abandone o modelo tradicional. Permite construir o processo ensinoaprendizagem junto aos alunos $e$ compartilhar a construção do conhecimento" (Diferença).

Não há nesse pensar julgamento de valor, mas o desocultamento das formas que impedem o enfermeiro-educador de desenvolver suas ações de modo autônomo, restando-Ihe apenas executar o trabalho já estabelecido, o que lhe causa muito sofrimento. Pois entendo, que as boas relações sociais no trabalho são importantes para qualquer tipo de trabalho em que convivam duas ou mais pessoas no mesmo ambiente, ou mesmo fisicamente distantes, mas ligadas diretamente pela atividade.

Todavia, se o enfermeiro-educador tem condições organizacionais ruins de trabalho e ainda assim se mostra muito bem, então é o próprio trabalho (valor de uso) e não o valor de troca que o move; é o próprio trabalho, e não as condições em que se realiza, o primeiro e o mais importante preditor dos altos níveis de satisfação, comprometimento, boa relação com o produto e centralidade no trabalho demonstrado por estes profissionais.

Neste contexto, observa-se no cotidiano, que enquanto muitos trabalhadores suportam o trabalho, e através do salário buscam satisfazer os seus desejos, os enfemeiros-educadores, ao contrário, suportam o salário para continuar tendo o privilégio da satisfazer um desejo que é o de todos nós, mudar o mundo através de nossas ações, transformar com nosso processo de trabalho a si mesmo e ao outro, inventar um futuro a partir de nossos próprios gestos. Estes gestos estão expressos através das falas de Utopia:

"Eu sou nova na escola. Conheço muito pouco os outros profissionais que dão aula. $E$ as relações com outros profissionais, fora o enfermeiro, não existem. Acho difícil essa relação, uma vez que não nos encontramos para discutirmos sobre o que está sendo dado para os alunos; como vamos conduzir estes alunos; a onde a gente quer chegar com esses alunos" (Utopia).

Ao analisar as relações educadoreducando no processo de trabalho, surgiram opiniões contraditórias que revelam que se entendermos "educação" como uma possibilidade de criação das condições para o desenvolvimento das potencialidades do ser humano, então parece ser ela um instrumento tanto para a conquista dessas habilidades como para uma adequada problematização dessa questão, possibilitando a criação de fontes alternativas de tomada de consciência pelos indivíduos envolvidos nesse contexto.

"Acho que o aluno é o reflexo do professor e vice-versa. Esta questão passa também pela motivação do aluno, do professor. Se o aluno começa a se desinteressar é porque alguma falha está havendo no processo de ensinoaprendizagem tanto do professor quanto 
da escola em sua estrutura. A escola, a direção ou quem está como responsável técnico tem que estar de 'olho', observando e acompanhando todo o processo" (Paradoxo).

Dessa forma, as implicações que esse aparente caos traz nas relações entre os educadores e os educandos são muitas e de muita responsabilidade, como se pode depreender. A primeira, de cunho mais filosófico, é de que a aprendizagem nesse nível, não ocorre através das relações assimétricas. Nesses moldes, torna-se mais adequada a figura de um facilitador de conhecimentos do que a tradicional figura do professor. Isso porque, o fluxo de informações é quase imensurável, o que dificulta o domínio delas e seu controle, impondo-se a necessidade delas circularem entre todos os interessados (KOURGANOFF, 1990). Outra implicação é a de que o mundo do trabalho funciona como um espaço de oportunidades, tendo maior oportunidade nesse mercado, o trabalhador que propõe uma nova demanda. Isso significa que somos, contraditoriamente e cada vez mais, uma sociedade que produz para trabalhar, ao invés de trabalhar para produzir (KOURGANOFF, 1990). Estas implicações contraditórias estão explicitadas quando Conscientização diz:

"As relações entre educador-educando são as mais variadas possíveis. Estas relações passam pela questão do poder e pela autonomia que a escola possui em absorver esses educandos. A maioria dos educandos não possui essa consciência, nem compromisso com ele próprio nem com o curso que está fazendo, mas não encontra outras perspectivas de trabalho e resolve fazer Enfermagem, pois é serviço certo, garantido. Por outro lado, o mercado de trabalho está absorvendo esse profissional" (Conscientização).

\section{TECENDO AS CONSIDERAÇÕES FINAIS}

Frente às questões evidenciadas, percebi através das expressões do grupo, que existe uma limitação no processo de trabalho, uma vez que o enfermeiro entende o seu papel de educador, norteado por questões extremamente técnicas. Por outro lado, observa-se que mesmo detendo este conhecimento técnico, estes profissionais tentam esconder os seus medos frente a cada situação singular e diversa, demonstrando nos seus gestos a ambivalência entre a onipotência e a fragilidade, a realização e a frustração, entre o medo e satisfação. Este fato é compreensível se considerarmos que o processo de trabalhos dos enfermeiroseducadores não é estático, mas, sim processual, ou seja, durante o seu percurso profissional vivem experiências que promovem alterações conceituais e práticas, mais ou menos lentas.

De modo geral, o saber em enfermagem produzido na academia atrelado à prática pedagógica, ainda, não tem uma ação efetiva, mas atua no imaginário dos enfermeiros-educadores e dos educandos. Isto é, da ordem da ficção, do que se deseja frente às coisas constituídas. Contudo, atribuo tais situações a fatores pessoais, culturais econômicos e sociais. Além disso, as visões de mundo diferenciadas a respeito do ser humano e a falta de consciência histórica, crítica e cientifica podem estar aguçando tais concepções, pois reconheço, que o ensino tradicional faz parte da vida dos educandos desde que ingressam na escola, não sendo a universidade a única responsável por tal formação.

Este ir e vir proporcionou ao grupo, a produção e a construção de novos conhecimentos, bem como nos fez refletir sobre nossa atuação na prática pedagógica de Enfermagem e da saúde e sobre que tipo de educandos estamos formando. É preciso salientar, que ao falar em reflexão-açãotransformação da prática pedagógica, isto não significa rejeitar o instituído, mas em refletir coletivamente e optar sobre o que é preciso conservar ou transformar. 
Em diversas falas dos participantes apareceu $o$ ato de aprender-ensinar também, como sofrimento. $\mathrm{O}$ ato de aprender-ensinar como sofrimento, me fez pensar na crise de identidade que os educadores estão experiênciando na atualidade. De forma mais ou menos direta, o conjunto de fatores que ingressam na configuração dessa crise apontam a um questionamento do saber e saber-fazer dos educadores, da sua competência para lidar com as exigências crescentes do mundo atual em matéria educativa e com uma realidade social cada vez mais deteriorada que impõe impasses constantes à atividade dos profissionais que atuam na prática de ensino de Enfermagem.

Todavia, a democracia na escola, visa romper com a separação entre a concepção e a execução, entre o pensar e o fazer, entre a teoria e a prática. Busca resgatar o controle do processo e do produto do trabalho por parte dos educadores, possibilitando 0 aperfeiçoamento e a formação continuada dos profissionais da educação e proporcionando a construção não apenas do técnico, mas de cidadãos, como agentes ativos, criador de sua própria história.

No entanto, penso que a educação do homem para o trabalho e pelo trabalho será a nova proposta pedagógica, pois, "já não se sustentam propostas pedagógicas que separam as funções intelectuais das funções técnicas; pelo contrário, o que se exige do homem moderno é uma formação que permita captar, compreender e atuar na dinamicidade do real, enquanto sujeito político e produtivo, que, potencialmente dirigente, tenha conhecimento científico e consciência de seus direitos e deveres para dominar a natureza e transformar as relações sociais, e isto também independe do nível de formação" (KUENZER, 1998, p. 24-5).

Neste contexto, se torna um desafio trabalhar na formação de profissionais, inclusive da área da saúde, especificamente os de enfermagem, pois, se por um lado os requisitos exigidos na formação destes profissionais pelo mercado são muitos, atendendo principalmente uma lógica empresarial capitalista, do outro está a responsabilidade e o compromisso ético de assumir uma formação que compartilha de uma política voltada para as necessidades da maioria da população (BAGNATO, 1997).

Diante da problemática explicitada, mas do que nunca, os educadores em geral, bem como os que estão atuando na prática pedagógica do ensino médio de Enfermagem, não poderão se eximir de uma reflexão que considere o sentido social, ideológico e político destas mudanças; e em que medida as escolas e as universidades, colaboram para explicitar as influências e conseqüências deste processo, tendo em vista que este é um importante papel social e educativo que elas tem a desempenhar.

Enfim, este compromisso implica também, considerar as diferentes dimensões presentes na educação: a técnica, a humana, a política, a histórica, a social, a cultural, a ética, a estética, a epistemológica, a filosófica, a psicológica, a afetiva, superando visões e concepções, lineares que tendem a alienar os sujeitos envolvidos no processo. Cumpre-nos aproveitar, com responsabilidade, as oportunidades tão duramente conquistadas, a fim de fazer crescer nossa participação na sociedade brasileira e usufruirmos tudo o que temos feito por merecer.

\section{REFERENCIAS BIBLIOGRAFICAS:}

ALVES, R. Entre a Ciência e a sapiência: o dilema da educação. 5 ed. São Paulo: Edições Loyola, 2001.

TRENTINI, M. ; PAIM, L. Pesquisa em Enfermagem: uma modalidade convergente-assistencial. Florianópolis: UFSC, 1999. (Série Enfermagem; REPENSUL -UFSC).

SIQUEIRA, H.G.S.; PORTELLA, M. R.;AREJANO, C. B. A produção do conhecimento: o construtivismo como estratégia metodológica. Rev. Texto e Contexto Enfermagem, Florianópolis, v. 9, n.1, p. $93-111,2000$. 
VYGOTSKY, L. S. A formação social da mente. São Paulo: Martins Fontes, 2000.

DEJOURS C. Psicodinâmica do Trabalho. São Paulo: Atlas, 1994.

ASSMANN, H. Reencantar a Educação. 5 ed. Petrópolis - Rio de Janeiro: Vozes; 2001.

ALVES, RUBENS. Alegria de ensinar. 2 ed. Campinas - São Paulo: Papirus; 2000.

DEJOURS, C. A Banalização da Injustiça Social. 4 ed. Rio de janeiro: FGV, 2001.

LUNARDI FILHO, W. D. Prazer e sofrimento no trabalho: contribuições à organização do processo de trabalho da enfermagem numa unidade de internação. Rev. Bras. Enfermagem, Brasília. V.50, n 1, p. 77-92, 1997.

DEJOURS, C. A loucura do Trabalho: estudo de psicopatologia de trabalho. São Paulo: Cortez. 2002.

KOURGANOFF, W. A face oculta da universidade. São Paulo: UNESP, 1990.

KUENZER, A. Z. Desafios teóricometodológicos da relação trabalhoeducação e o papel social da escola. In: FRIGOTTO, G. Educação e crise do trabalho: perspectivas de final de século. Petrópolis: Vozes, 1998.

BAGNATO, M. H. S. Concepções Pedagógicas no Ensino de Enfermagem no Brasil. Revista Texto e Contexto Enfermagem, Florianópolis, V.6, n.3, p. 241-258, 1997.

Texto original recebido em 12/12/2003.

Publicação aprovada em 30/04/2004. 